\title{
Sistem bandwidth WiFi jaringan ad-hoc menggunakan metode class based queue
}

\author{
Teddi Hariyanto ${ }^{1 *}$, Maya Rahayu ${ }^{2}$ \\ ${ }^{1,2}$ Jurusan Teknik Elektro, Politeknik Negeri Bandung \\ Jl. Gegerkalong Hilir, Ciwaruga, Kec. Parongpong, Kabupaten Bandung Barat, Jawa Barat, Indonesia \\ 1* ${ }^{*}$ teddi.hariyanto@polban.ac.id, ${ }^{2}$ mayarahayu@polban.ac.id
}

\begin{abstract}
ABSTRAK
Mobile ad-hoc network (MANET) merupakan jaringan ad-hoc yang dibangun oleh perangkat-perangkat bergerak, salah satunya adalah laptop. Jaringan tersebut merupakan jaringan nirkabel yang bersifat infrastructureless. Jaringan ini mampu mengkomunikasikan node secara peer-to-peer tanpa basic service set (BSS). Ketidakberadaan BSS pada jaringan ini menyulitkan para pengguna dalam mengalokasikan uplink bandwidth bagi node/link kritikal dan mencegah terjadinya flooding pada jaringan. Penelitian ini bertujuan untuk merancang sebuah bandwidth management tool berupa program yang diimplementasikan untuk mengalokasikan uplink bandwidth pada jaringan ad-hoc. Program yang dirancang menggunakan metode CBQ untuk classifying dan scheduling paket. Dari hasil pengujian, sistem bandwidth WiFi jaringan ad-hoc menggunakan metode CBQ ini memiliki kinerja throughput 513,24 Kbps yang diperoleh melalui perhitungan average rounded trip time.
\end{abstract}

Kata kunci: MANET, bandwidth management tool, CBQ

\section{ABSTRACT}

Mobile ad-hoc network (MANET) is an ad-hoc network built by mobile devices, one of which is a laptop. The network is a wireless network that is infrastructureless. This network is capable of communicating peer-topeer nodes without a basic service set (BSS). The absence of a BSS on this network makes it difficult for users to allocate uplink bandwidth for critical nodes / links and prevents flooding on the network. This research aims to design a bandwidth management tool in the form of a program that is implemented to allocate uplink bandwidth on an ad-hoc network. The program is designed using the CBQ method for classifying and scheduling packages. From the test results, the ad-hoc network bandwidth WiFi system using the CBQ method has a throughput performance of 513.24 Kbps which is obtained through the calculation of average rounded trip time.

Keywords: MANET, bandwidth management tool, $C B Q$

\section{PENDAHULUAN}

Saat ini, teknologi komunikasi nirkabel (wireless) mengalami perkembangan yang cukup signifikan. Hal ini ditandai dengan adanya penelitian yang dilakukan oleh kalangan akademisi maupun perusahaan-perusahaan pengembang telekomunikasi mengenai teknologi wireless. Beberapa penelitian tersebut diantaranya adalah penelitian mengenai perencanaan wireless local area network (WLAN) berdasarkan model optimasi dan algoritma multi-agen [1]. Desain WLAN yang aman dengan menggunakan firewall packet filtering juga telah dikaji pada penelitian [2]. Pada penelitian [3], alat untuk mendeteksi manusia luar ruang non-line-of-sight (NLOS) berbasis deep neural network (DNN) menggunakan sinyal WLAN IEEE 802.11 ac telah dirancang. Ada pula yang membuat antena WLAN multi-input multi-output (MIMO) dengan antena global positioning system (GPS) untuk aplikasi jam tangan pintar [4]. Analisis kinerja tautan WLAN menggunakan quadrature amplitude modulation (QAM) dan quadrature phase shift keying (QPSK) berdasarkan transceiver sinyal vektor 5644R telah disampaikan pada [5]. Terakhir, penelitian [6] telah membuat pembatasan flooding area berbasis lokasi untuk jaringan ad-hoc.

Mobile ad-hoc network (MANET) merupakan jaringan ad-hoc yang dibangun oleh perangkatperangkat bergerak, salah satunya adalah laptop. Jaringan MANET merupakan merupakan jaringan nirkabel yang bersifat infrastructureless. Permasalahan pada jaringan MANET adalah tidak adanya base service set (BSS) yang dapat menyulitkan para pengguna. Berbagai penelitian telah dilakukan 
pada jaringan MANET. Penelitian [7] telah menganalisis performa protokol perutean MANET untuk streaming video. Kemudian pada [8] telah dianalisis kapasitas MANET 3D di bawah redundansi paket dan probing penerima. Selanjutnya timer dinamis berdasarkan durasi tautan yang diharapkan di jaringan ad-hoc seluler telah dikembangkan [9]. Analisis batasan operasional jaringan ad-hoc seluler juga telah dilakukan pada penelitian [10]. Penelitian [11] telah merancang jaringan ad-hoc seluler berbasis WiFi langsung. Pada [12] telah dirancang teknik mitigasi serangan lubang hitam di jaringan ad-hoc seluler. Peneliti [13] telah merancang cloud ad-hoc seluler untuk sistem pengawasan video otomatis dengan peringatan pesan. Terakhir, penelitian [14] telah merancang sistem berbagi sumber daya berbasis hotspot untuk jaringan ad-hoc seluler.

Tujuan penelitian ini adalah merancang sebuah bandwidth management tool berupa program yang diimplementasikan untuk mengalokasikan uplink bandwidth pada jaringan ad-hoc. Untuk mengatasi hal ini, beberapa model quality of service (QoS) telah dikaji, diantaranya adalah class based (CBQoS) [15] dan class based queuing (CBQ) [16]. Namun, pengujian kedua model tersebut masih sebatas simulasi. Penelitian ini dilakukan dengan metode eksperimen. Pada penelitian ini, program dirancang menggunakan metode CBQ untuk klasifikasi dan penjadwalan paket.

\section{METODE PENELITIAN}

\subsection{Perancangan Program}

Pada penelitian ini, program yang dirancang merupakan bandwidth management tool. Sistem kerja tool ini diperlihatkan oleh Gambar 1.

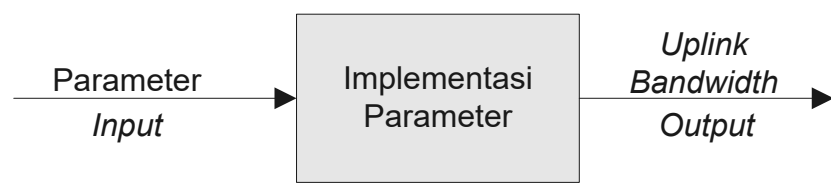

Gambar 1. Diagram blok program

Pada intinya, program ini berfungsi untuk mengalokasikan uplink bandwidth. Hal tersebut dimaksudkan untuk menghindari flooding yang disebabkan karena berlebihnya transmisi data dari tiap node. Dengan adanya upaya ini, bandwidth yang tersedia dapat dialokasikan sedemikian rupa untuk digunakan oleh node yang bersifat kritikal. Proses pengalokasian bandwidth tersebut dilakukan dengan mengatur classifying, scheduling, dan shaping data. Kedua proses tersebut ditentukan oleh parameterparameter input. Parameter-parameter tersebut adalah sebagai berikut:

1. Parameter CBQ. Parameter ini mempengaruhi classifying dan scheduling data. Parameter ini meliputi flow ID, protokol yang digunakan, dan IP address node pengirim. Flow ID merupakan identifikasi flow description yang memuat parameter shaping. Protokol dapat berupa transmission control protocol/internet protocol (TCP/IP) atau user datagram protocol (UDP), sedangkan IP address merupakan Ipv4.

2. Parameter shaping. Parameter ini bernama throttle rate dan berfungsi untuk mengatur shaping data dan uplink bandwidth untuk masing-masing node.

Program yang dirancang memiliki dua mode kerja, yaitu server mode atau client mode. Server mode merupakan suatu kondisi dimana program ini berperan sebagai penentu parameter CBQ dan shaping. Hasil penentuan ini akan di-broadcast ke seluruh jaringan dan diimplementasikan pada masing-masing node. Model kerja ini terdapat pada Gambar 2 dan algoritma kerja program secara keseluruhan ditunjukan oleh Gambar 3 (a). Algoritma kerja server mode dan client mode, secara umum ditunjukan oleh Gambar 3(b) dan Gambar 3(c). 


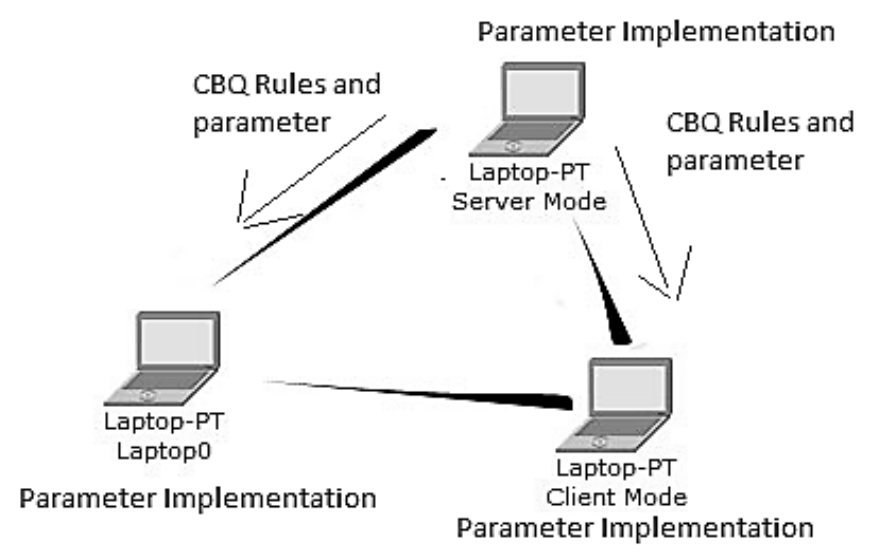

\section{Gambar 2. Model kerja program}

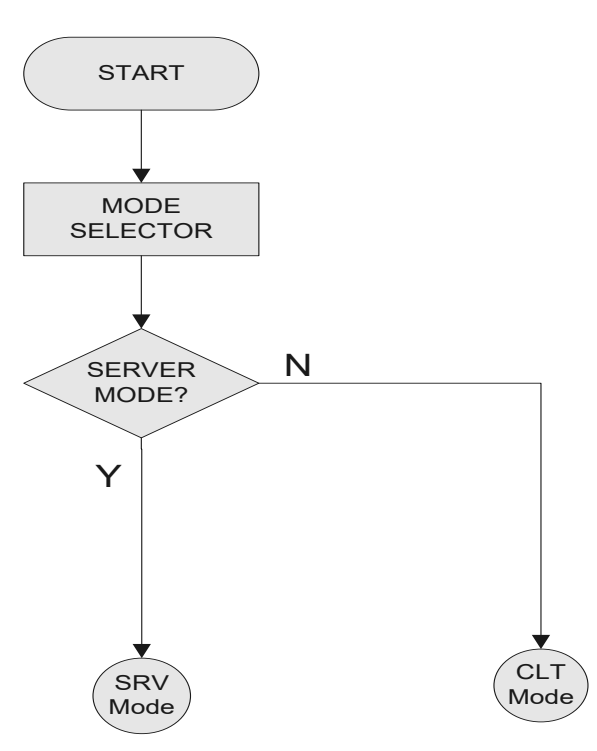

(a)

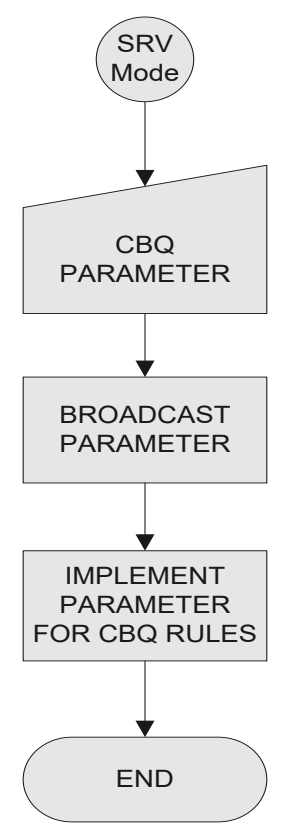

(b)

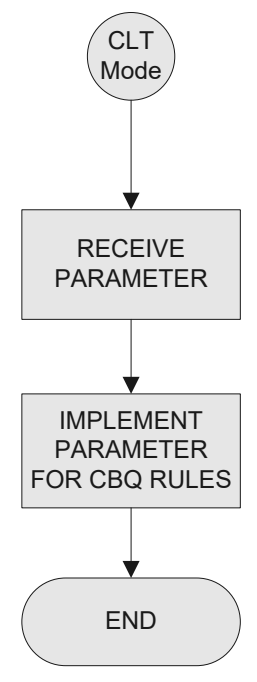

(c)

Gambar 3. Algoritma program yang dirancang: (a) algoritma keseluruhan, (b) algoritma server mode, (c) algoritma client mode

\subsection{Perancangan Jaringan}

Pada penelitian ini, jaringan yang dirancang merupakan jaringan MANET, yang dibangun oleh tujuh laptop. Spesifikasi minimal dari laptop yang digunakan adalah sistem operasi Windows 7 dan dilengkapi wireless NIC untuk standar IEEE $802.11 \mathrm{~b} / \mathrm{g} / \mathrm{n}$. Adapun topologi jaringan ini terdapat pada Gambar 4. Pada gambar tersebut, jarak antar laptop (r) lebih kecil dibandingkan jari-jari sel (R), dimana R sama dengan 30 kaki atau sekitar 9 meter. 


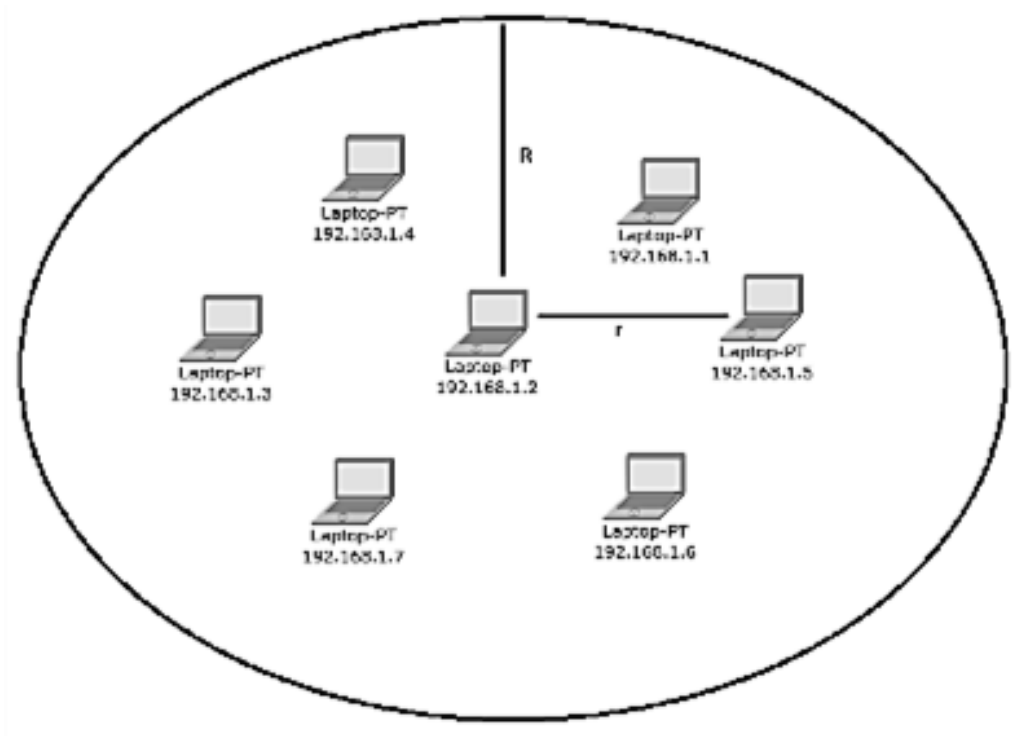

Gambar 4. Topologi jaringan ad-hoc 7 laptop

\section{HASIL DAN PEMBAHASAN}

\subsection{Skenario dan Hasil Pengukuran}

Parameter masukan untuk skenario dan hasil pengujian ini dilakukan berdasarkan pada skenario parameter pada Tabel 1. Gambar 5 memperlihatkan hasil pengukuran average round trip times dari alamat IP 192.168.1.2-192.168.1.7 ke 192.168.1.1. Gambar 6 memperlihatkan hasil pengukuran average response times dari alamat IP 192.168.1.2-192.168.1.7 ke 192.168.1.1. Gambar 7 . memperlihatkan hasil pengukuran throughput dari alamat IP 192.168.1.2-192.168.1.7 ke 192.168.1.1.

Tabel 1. Skenario parameter input

\begin{tabular}{|c|l|c|c|}
\hline Flow No. & IP Address & Protocol & Throttle Rate (Bps) \\
\hline 1 & 192.168 .1 .1 & TCP/IP & 100000 \\
\hline 2 & 192.168 .1 .2 & TCP/IP & 200000 \\
\hline 3 & 192.168 .1 .3 & TCP/IP & 300000 \\
\hline 4 & 192.168 .1 .4 & TCP/IP & 400000 \\
\hline 5 & 192.168 .1 .5 & UDP & 500000 \\
\hline 6 & 192.168 .1 .6 & UDP & 600000 \\
\hline 7 & 192.168 .1 .7 & UDP & 700000 \\
\hline
\end{tabular}
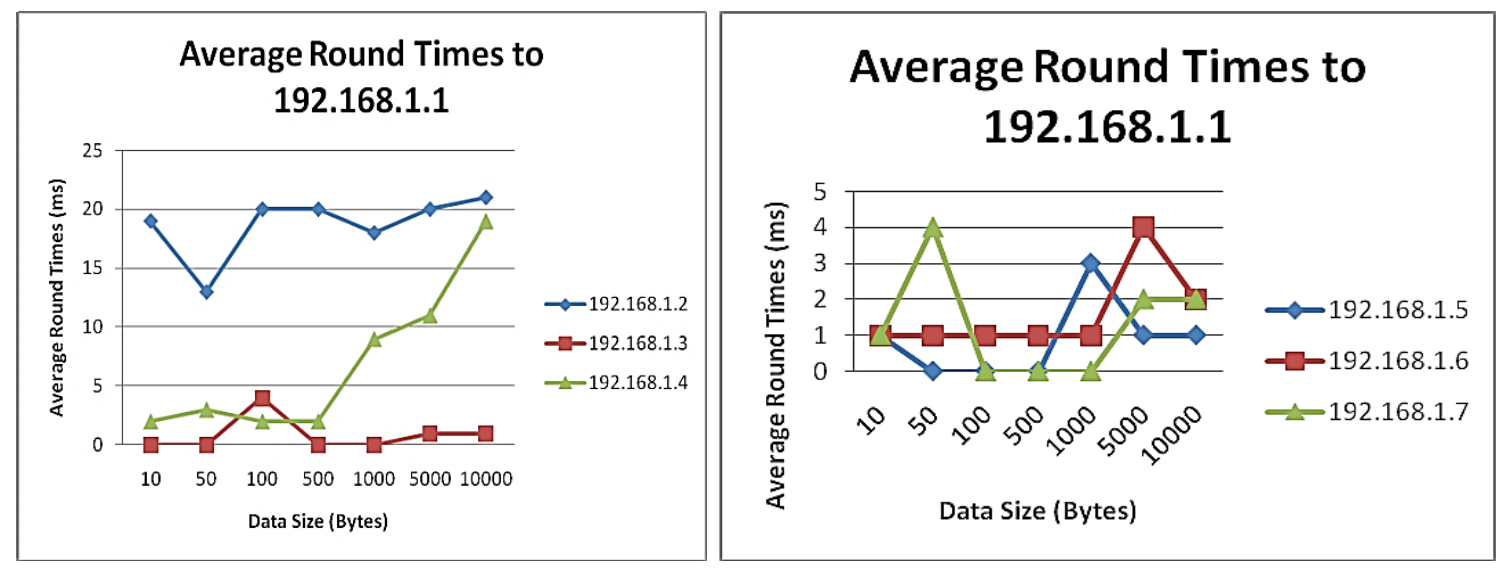

Gambar 5. Grafik average round trip times ke 192.168.1.1 


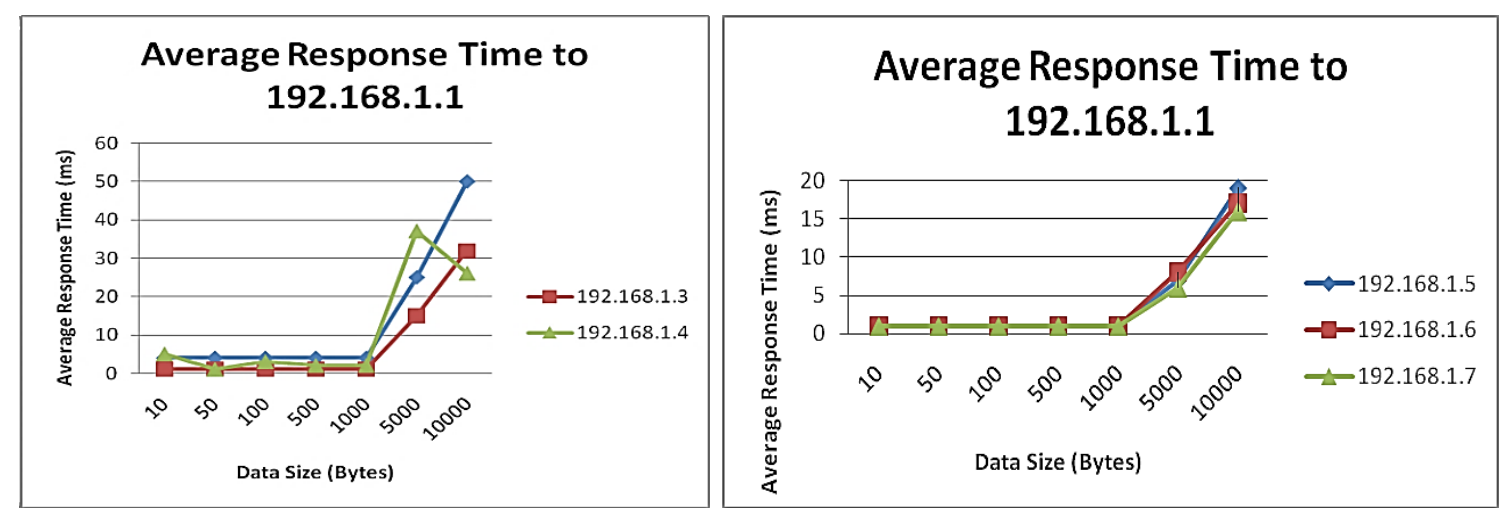

Gambar 6. Grafik average response time ke 192.168.1.1
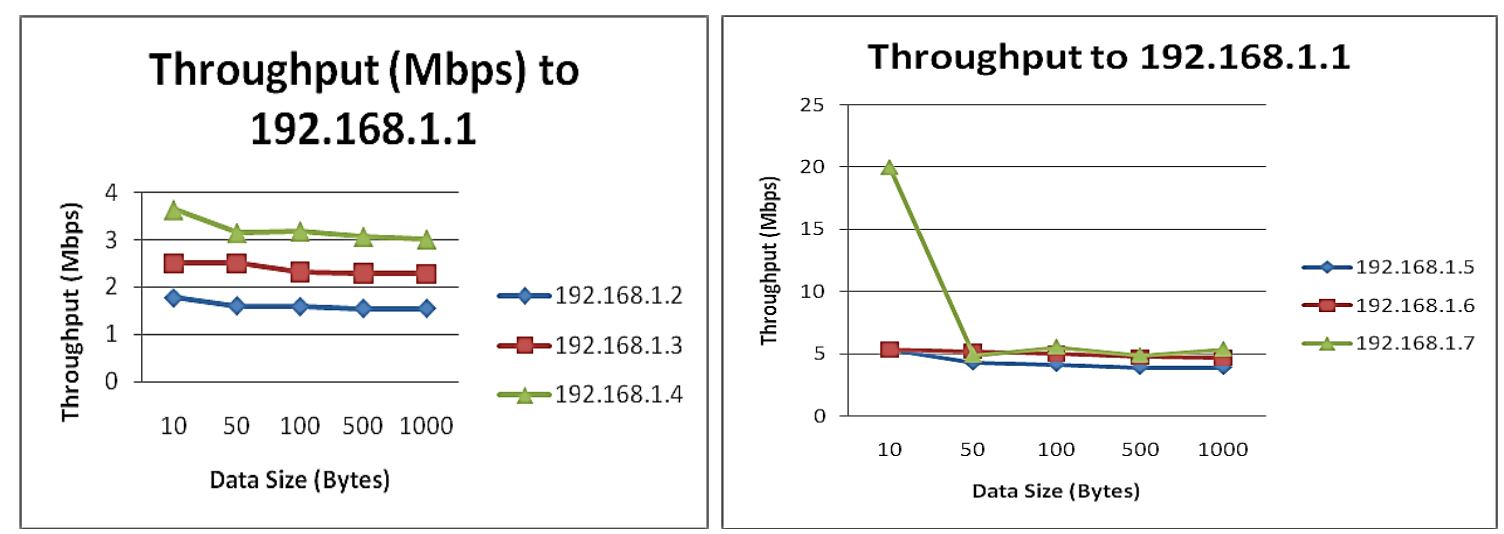

Gambar 7. Grafik throughput (Mbps) ke 192.168.1.1

Berdasarkan hasil pengukuran average round trip times dan average response times, nilai throughput dapat dihitung. Hasil perhitungan tersebut terdapat pada Tabel 2 dan Tabel 3. Nilai throughput hasil pengukuran, dapat dikonversi ke dalam satuan Kbps seperti pada Tabel 4.

Tabel 2. Perhitungan throughput berdasarkan average round trip times

\begin{tabular}{|c|c|c|c|c|c|c|c|}
\hline \multirow{2}{*}{ IP Address } & \multicolumn{7}{|c|}{ Data size (Bytes) } \\
\cline { 2 - 8 } & $\mathbf{1 0}$ & $\mathbf{5 0}$ & $\mathbf{1 0 0}$ & $\mathbf{5 0 0}$ & $\mathbf{1 0 0 0}$ & $\mathbf{5 0 0 0}$ & $\mathbf{1 0 0 0 0}$ \\
\hline 192.168 .1 .2 & 0,53 & 3,85 & 5 & 25 & 55,56 & 250 & 476,19 \\
\hline 192.168 .1 .3 & - & - & 25,00 & - & - & 5000,00 & 10000,00 \\
\hline 192.168 .1 .4 & 5,00 & 16,67 & 50,00 & 250,00 & 111,11 & 454,55 & 526,32 \\
\hline 192.168 .1 .5 & 10,00 & - & - & - & 333,33 & 5000,00 & 10000,00 \\
\hline 192.168 .1 .6 & 10 & 50 & 100 & 500 & 1000 & 1250 & 5000 \\
\hline 192.168 .1 .7 & 10 & 12,5 & - & - & - & 2500 & 5000 \\
\hline
\end{tabular}

Tabel 3. Perhitungan throughput berdasarkan average response time

\begin{tabular}{|c|c|c|c|c|c|c|}
\hline \multirow{2}{*}{ IP Address } & \multicolumn{7}{|c|}{ Data size (Bytes) } \\
\cline { 2 - 7 } & $\mathbf{1 0}$ & $\mathbf{5 0}$ & $\mathbf{1 0 0}$ & $\mathbf{1 0 0 0}$ & $\mathbf{5 0 0 0}$ & $\mathbf{1 0 0 0 0}$ \\
\hline 192.168 .1 .2 & 2,5 & 12,5 & 25 & 250 & 200 & 200 \\
\hline 192.168 .1 .3 & 10 & 50 & 100 & 1000 & 333,33 & 312,5 \\
\hline 192.168 .1 .4 & 2 & 50 & 33,33 & 500 & 135,14 & 384,62 \\
\hline 192.168 .1 .5 & 10 & 50 & 100 & 1000 & 714,29 & 526,32 \\
\hline 192.168 .1 .6 & 10 & 50 & 100 & 1000 & 625 & 588,24 \\
\hline 192.168 .1 .7 & 10 & 50 & 100 & 1000 & 833,33 & 625 \\
\hline
\end{tabular}


Tabel 4. Hasil pengukuran throughput (Kbps)

\begin{tabular}{|c|c|c|c|c|c|}
\hline \multirow{2}{*}{ IP Address } & \multicolumn{5}{|c|}{ Data size (kBytes) } \\
\cline { 2 - 6 } & $\mathbf{1 0}$ & $\mathbf{5 0}$ & $\mathbf{1 0 0}$ & $\mathbf{5 0 0}$ & $\mathbf{1 0 0 0}$ \\
\hline 192.168 .1 .2 & 222,25 & 200,75 & 198,75 & 193,75 & 193,75 \\
\hline 192.168 .1 .3 & 312,5 & 312,5 & 290,75 & 287,5 & 286,25 \\
\hline 192.168 .1 .4 & 454,625 & 393,75 & 398,38 & 384 & 376,88 \\
\hline 192.168 .1 .5 & 666,75 & 531,88 & 516,25 & 487,75 & 486,38 \\
\hline 192.168 .1 .6 & 666,75 & 649,38 & 625 & 590,38 & 582,13 \\
\hline 192.168 .1 .7 & 2500,25 & 609,75 & 694,5 & 611,25 & 672,5 \\
\hline
\end{tabular}

Dari informasi pada Tabel 4, dapat disimpulkan bahwa throughput yang diperoleh melalui perhitungan average rounded time tidak mengalami pembatasan. Hal ini terjadi, karena paket data yang dikirimkan pada fasilitas ping command prompt tidak mengalami shaping. Hal ini terjadi karena paket-paket tersebut tidak menggunakan protokol TCP maupun UDP. Kondisi ini dapat dibuktikan dengan menggunakan packet capping software.

Pada beberapa data size, throughput melebihi throttle rate yang ditetapkan dengan selisih yang cukup jauh. Hal ini terjadi, karena response time merupakan waktu yang diperlukan data selama proses pengiriman dari node pengirim ke node penerima dan sebaliknya. Hal ini juga dapat dibuktikan dengan menggukanan packet capping software. Dengan kata lain, troughput yang diperoleh melalui perhitungan average response time, merupakan troughput total dibagi upstream troughput ditambah downstream troughput. Nilai troughput total ini, berada di bawah nilai throttle total seperti pada persamaan (1), dengan syarat response time lebih besar dari $1 \mathrm{~ms}$. Hal ini menjadi prasyarat utama, karena $1 \mathrm{~ms}$ merupakan satuan terkecil dari response time yang dapat diukur oleh Qcheck.

$$
\text { Trottle total }=\text { throttle pengirim }+ \text { throttle penerima }
$$

$$
\text { Throughput }=\frac{\text { Data Sent }+ \text { Date Receive }}{\text { Measured Time }} \mathrm{bit} / \mathrm{sec}
$$

Pada data size rendah, troughput melebih throttle rate, sedangkan pada data size tinggi, troughput berada di bawah throttle rate. Hal ini terjadi karena Qcheck mengukur troughput dengan menggunakan persamaan (2). Apabila ukuran data yang dikirm terlalu kecil, maka waktu pengukuran pun akan terlalu cepat, sehingga hasil pengukuran tidak bisa diandalkan. Hal ini dibuktikan dengan munculnya warning message pada Qcheck saat pengukuran troughput alamat IP 192.168.1.7 dengan data size sebesar 10 bytes seperti pada seperti ditunjukkan Gambar 8.

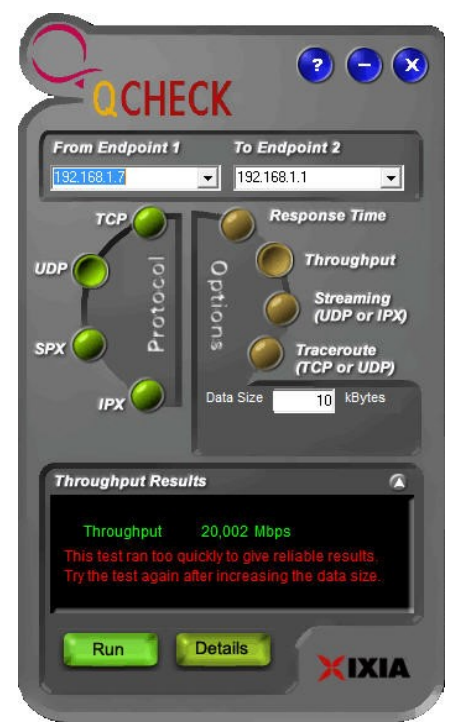

Gambar 8. Warning message pada Qcheck 


\section{KESIMPULAN}

Berdasarkan hasil desain dan impelentasi bandwidth management tool jaringan ad-hoc tujuh laptop, dapat disimpulkan bahwa sistem yang dirancang mampu mengalokasikan uplink bandwidth untuk node pada protokol tertentu. Nilai dari bandwidth tersebut ditentukan oleh parameter throttle rate yang dimasukkan oleh user pada mode server. Bandwidth management tool yang didesain mampu dan compatible untuk bekerja pada laptop dari berbagai manufaktur, selama laptop tersebut menggunakan sistem operasi Windows 7. Selain itu, sistem yang dibuat mampu mempengaruhi dan membatasi upstream throughput untuk node pada protokol tertentu. Tingkat kepresisian pembatasan, bergantung pada besar data yang dikirimkan. Saran untuk penelitian berikutnya adalah dapat melakukan perancangan sistem bandwidth WiFi jaringan ac-hoc menggunakan metode lain yang memiliki parameter kinerja yang lebih baik dari metode CBQ.

\section{REFERENSI}

[1] Y. Zheng, T. Shi, X. Xu, H. Yuan, and T. Yao, "Research on WLAN planning problem based on optimization models and multi-agent algorithm," 2017 IEEE Int. Conf. Cybern. Intell. Syst. CIS 2017 IEEE Conf. Robot. Autom. Mechatronics, RAM 2017 - Proc., vol. 2018-January, pp. 249-254.

[2] H. M. T. Al-Hilfi, B. A. Salih, and I. Marghescu, "Design of secured WLAN by using "packet filtering firewall,"” Proc. 2017 Int. Conf. Wirel. Commun. Signal Process. Networking, WiSPNET 2017, vol. 2018January, pp. 1857-1862, 2018.

[3] R. Takahashi, S. Ishida, A. Fukuda, T. Murakami, and S. Otsuki, "DNN-based Outdoor NLOS Human Detection Using IEEE 802.11ac WLAN Signal," Proc. IEEE Sensors, vol. 2019-October, pp. 1-4, 2019.

[4] W. S. Chen, G. Q. Lin, and W. H. Hsu, "WLAN MIMO antennas with a GPS antenna for smart watch applications," 2017 Int. Work. Electromagn. Appl. Student Innov. Compet. iWEM 2017, no. c, pp. 89-90, 2017.

[5] G. Soni and C. Verma, "Performance investigation of the WLAN link using QAM and QPSK based on vector signal transceiver 5644R," Proc. - 7th Int. Conf. Commun. Syst. Netw. Technol. CSNT 2017, pp. 34 $37,2018$.

[6] M. A. H. Networks, "Location-based Flooding Area Restriction for," 2019 20th Asia-Pacific Netw. Oper. Manag. Symp., pp. 1-4, 2019.

[7] N. Rathod and N. Dongre, "MANET routing protocol performance for video streaming," 2017 Int. Conf. Nascent Technol. Eng. ICNTE 2017 - Proc., 2017.

[8] W. Wang, B. Yang, X. Wang, Y. She, and S. Shen, "Capacity of 3D MANETs under packet redundancy and receiver probing," Proc. - 2018 Int. Conf. Netw. Netw. Appl. NaNA 2018, pp. 164-168, 2019.

[9] B. S. Kim, D. G. Majengo, K. Il Kim, B. S. Roh, and J. H. Ham, "Dynamic Timer Based on Expected Link Duration in Mobile Ad-hoc Networks," Proc. - 2019 IEEE 16th Int. Conf. Mob. Ad-hoc Smart Syst. Work. MASSW 2019, pp. 158-159, 2019.

[10] K. Muralidhar and K. Madhavi, "An investigation into the operational limitations of mobile ad-hoc networks," Proc. 2017 Int. Conf. Wirel. Commun. Signal Process. Networking, WiSPNET 2017, vol. 2018January, pp. 1373-1376.

[11] J. H. Lee, M. S. Park, and S. C. Shah, "Wi-Fi direct based mobile ad-hoc network," 2nd Int. Conf. Comput. Commun. Syst. ICCCS 2017, pp. 116-120, 2017.

[12] S. H. Omprakash and M. K. Suthar, "Mitigation Technique for Black hole Attack in Mobile Ad-hoc Network," 2020 11th Int. Conf. Comput. Commun. Netw. Technol. ICCCNT 2020, 2020.

[13] R. Chaithra and A. S. Poornima, "A Mobile AD-HOC Cloud for Automated Video Surveillance System with Message Alert," Proc. 2nd Int. Conf. Trends Electron. Informatics, ICOEI 2018, pp. 1171-1175, 2018.

[14] B. Cui and Y. Yang, "Hotspot-based Resource Sharing System for Mobile Ad-hoc Networks," Proc. 2018 IEEE 8th Int. Conf. Electron. Inf. Emerg. Commun. ICEIEC 2018, pp. 146-149, 2018.

[15] M. El Amine Fekair, A. Lakas, and A. Korichi, "CBQoS-Vanet: Cluster-based artificial bee colony algorithm for QoS routing protocol in VANET," 2016 Int. Conf. Sel. Top. Mob. Wirel. Networking, MoWNeT 2016, pp. 0-7, 2016.

[16] D. W. Sudiharto, F. A. Yulianto, and A. N. Arista, "Comparative analysis of voice over internet protocol (VoIP) quality on priority queue (PQ) and class-based queue (CBQ) management system using link-sharing mechanism setting," 2015 3rd Int. Conf. Inf. Commun. Technol. ICoICT 2015, pp. 419-424, 2015. 
